\title{
Microtubule Organization and Stability in the Oligodendrocyte
}

\author{
Katharine F. Lunn, ${ }^{1,2}$ Peter W. Baas, ${ }^{3}$ and Ian D. Duncan 1 \\ ${ }^{1}$ Department of Medical Sciences, ${ }^{2}$ Neuroscience Training Program, and ${ }^{3}$ Department of Anatomy, University of \\ Wisconsin-Madison, Madison, Wisconsin 53706
}

\begin{abstract}
The oligodendrocyte is the glial cell responsible for the formation and maintenance of CNS myelin. Because the development of neuronal morphology is known to depend on the presence of highly organized microtubule arrays, it may be hypothesized that the properties of microtubules influence the form and function of oligodendrocytes. The goals of the present study were to define the physical attributes of microtubules in oligodendrocytes maintained in vitro. The results of electron and confocal microscopy indicate that microtubules are present throughout the cell bodies and large and small processes of oligodendrocytes and are rarely associated with discrete microtubule-organizing centers. A modified "hooking" protocol demonstrated that the polarity orientation of microtubules is uniformly plus-end distal in small oligodendrocyte pro-
\end{abstract}

cesses, compared with a nonuniform, predominantly plus-end distal orientation in large processes. Oligodendrocytes were exposed to the microtubule-depolymerizing drug nocodazole to examine microtubule stability in these cells. The results suggest that oligodendrocyte microtubules can be resolved into at least three distinct microtubule populations that differ in their kinetics of depolymerization in the presence of nocodazole. These findings suggest that the properties of the oligodendrocyte microtubule array reflect the functions of the different regions of this highly specialized cell.

Key words: oligodendrocyte; myelination; microtubule; cytoskeleton; microtubule polarity; microtubule stability; nocodazole
The neurons and glial cells of the nervous system have complex morphologies that are intimately associated with their functions. The generation and maintenance of these morphologies require the establishment of highly organized arrays of microtubules within the cytoplasm of these cells. Microtubules are structural polymers that support the architecture of the cell and also provide a substrate for the active transport of cytoplasmic constituents. The role of microtubules in the differentiation of neurons has been examined in detail. Neurons extend two distinct types of process, axons and dendrites, that differ in their morphology and cytoplasmic composition. Many of these differences arise from the fact that microtubules in the axon are uniformly oriented with their plus-ends distal to the cell body, whereas microtubules in the dendrite have a nonuniform polarity orientation (Baas et al., 1988, 1989, 1991; Burton, 1988). These distinct microtubule patterns dictate the complement of cytoplasmic organelles that are transported into each type of process and help establish morphological features such as the greater length of the axon and the tapering morphology of the dendrite (Black and Baas, 1989).

Although analyses of microtubules have provided significant insight into the cell biology of the neuron, relatively little is known about microtubule arrays within other cell types of the nervous system. One cell of particular importance is the oligodendrocyte, a glial cell that is specialized for the formation of myelin in the CNS. Oligodendrocytes are derived from mitotic progenitor cells that are initially monopolar and then become bipolar and migra-

Received Jan. 27, 1997; revised April 9, 1997; accepted April 11, 1997.

This work was supported by National Institutes of Health Grant NS32361. Excellent technical assistance was provided by the personnel of the laboratories of Drs Duncan and Baas. We are also grateful to M. K. Clayton for help with the statistical analysis.

Correspondence should be addressed to Dr. Ian D. Duncan, Department of Medical Sciences, School of Veterinary Medicine, University of Wisconsin-Madison, 2015 Linden Drive West, Madison, WI 53706.

Copyright (C) 1997 Society for Neuroscience 0270-6474/97/174921-12\$05.00/0 tory (Small et al., 1987; Warf et al., 1991). Mature multipolar oligodendrocytes extend processes that contact and spiral around axons, ultimately forming the compact myelin sheath of the CNS. The assembly of the components of the myelin sheath requires the regulated synthesis, sorting, and transport of lipids and proteins and their coordinated insertion into the oligodendrocyte plasma membrane (Trapp, 1990; Brown et al., 1993). A number of studies have suggested that microtubules are essential for these complex events. For example, it has been shown that treatment of cultured oligodendrocytes with the microtubule-stabilizing drug taxol compromises the maintenance of their membrane sheets (Benjamins and Nedelkoska, 1994), whereas the microtubule-depolymerizing drug colchicine decreases the entry of proteolipid proteins into myelin in brain slices (Bizzozero et al., 1982). It also seems that the mRNA for the major myelin protein, myelin basic protein (MBP), is transported into oligodendrocyte processes in the form of granules that associate with microtubules (Ainger et al., 1993).

The present studies explore fundamental features of the oligodendrocyte microtubule array, using primary glial cultures as a model. The latter demonstrate many in vivo characteristics of oligodendrocytes, including the elaboration and maintenance of processes and membrane sheets, and the expression and compartmentalization of myelin-specific antigens (Knapp et al., 1987). Our data demonstrate differences in microtubule organization, stability, and polarity orientation in small and large oligodendrocyte processes. The specific features of the microtubule arrays within different regions of the oligodendrocyte provide new insight into the means by which this important cell type achieves its complex morphology and performs its essential functions.

\section{MATERIALS AND METHODS}

\section{Cell culture}

Sprague Dawley rat pups were euthanized by an overdose of barbiturate at $10 \mathrm{~d}$ of age. The spinal cords were removed under sterile conditions 
and placed in Leibovitz-15 medium (L-15) (Life Technologies, Grand Island, $\mathrm{NY}$ ) at $4^{\circ} \mathrm{C}$, and the meninges and nerve roots were removed. The cords were transferred to $\mathrm{Ca}^{2+}-$ and $\mathrm{Mg}^{2+}$-free Earle's balanced salt solution (EBSS) (Life Technologies) with $0.25 \%$ trypsin (Worthington, Freehold, NJ) and $0.05 \%$ DNase (Sigma, St. Louis, MO). The tissue was minced into $1 \mathrm{~mm}^{3}$ pieces and incubated in the enzyme solution in 5\% $\mathrm{CO}_{2}$ at $37^{\circ} \mathrm{C}$, on a rotating shaker at $70 \mathrm{rpm}$, for $60-90 \mathrm{~min}$. The trypsin was inactivated by the addition of heat-inactivated fetal bovine serum (HIFBS) (Life Technologies) to a final concentration of 20\%, and the tissue was recovered by centrifugation and resuspended in L-15 with $10 \%$ HIFBS. The final dissociation step involved trituration of the tissue at $4^{\circ} \mathrm{C}$ with flame-polished Pasteur pipettes of decreasing tip orifice size. The resulting cell suspension was diluted to $6.5 \mathrm{ml}$ with L-15/10\% HIFBS, mixed with $3 \mathrm{ml}$ of $80 \%$ Percoll (Sigma) in $0.25 \mathrm{M}$ sucrose buffered with $0.05 \mathrm{M}$ sodium phosphate at $\mathrm{pH} 7.4$, and centrifuged at $30,000 \times g$ for 45 $\mathrm{min}$. The oligodendrocyte-containing band was harvested from the bottom of the gradient, immediately above the red blood cell layer. The cells were suspended in L-15/10\% HIFBS and recovered by centrifugation. The pellet was resuspended in culture medium, and a cell count was obtained from a $15 \mu \mathrm{l}$ aliquot with use of a hemocytometer.

Cells were plated onto poly-L-lysine (Sigma)-treated $12 \mathrm{~mm}$ glass coverslips at a density of 30,000 cells/coverslip for nocodazole treatment and indirect immunofluorescent antibody staining. Cultures for electron microscopy (EM) and the hooking protocol were plated onto poly-Llysine-treated $35 \mathrm{~mm}$ plastic tissue culture dishes at a density of 50,00060,000 cells/dish. The cells were maintained in medium consisting of DMEM with 1:1 F-12 nutrient mixture (DMEM/F-12) (Life Technologies) supplemented with $100 \mu \mathrm{M}$ putrescine, $20 \mathrm{~nm}$ progesterone, $30 \mathrm{nM}$ sodium selenite, $5 \mu \mathrm{g} / \mathrm{ml}$ insulin, $10 \mu \mathrm{g} / \mathrm{ml}$ rat transferrin (Jackson ImmunoResearch, West Grove, PA), $40 \mathrm{ng} / \mathrm{ml}$ L-thyroxine, $30 \mathrm{ng} / \mathrm{ml}$ 3,3',5triiodo-L-thyronine, and $0.1 \mathrm{mg} / \mathrm{ml}$ bovine serum albumin (all components from Sigma, unless noted otherwise). The medium was supplemented further with $1 \%$ HIFBS and $0.1 \%$ gentamicin (Life Technologies).

The cultures were maintained in a $5 \% \mathrm{CO}_{2}$ environment at $37^{\circ} \mathrm{C}$. The medium was changed 24 and $48 \mathrm{hr}$ after plating, and the cells were used for additional studies after $4 \mathrm{~d}$ in vitro.

\section{Indirect immunofluorescence}

Glial cell cultures grown on glass coverslips were rinsed briefly with PHEM buffer (60 mM PIPES, $25 \mathrm{~mm}$ HEPES, $10 \mathrm{~mm}$ EGTA, $2 \mathrm{~mm}$ $\mathrm{MgCl}_{2}, \mathrm{pH}$ 6.9) followed by a 2 min extraction in $0.1 \%$ Triton X-100 in PHEM supplemented with $10 \mu \mathrm{M}$ taxol (a gift from the National Cancer Institute). The cultures were fixed by the addition of an equal volume of PHEM containing $4 \%$ paraformaldehyde and $0.2 \%$ glutaraldehyde. After fixation for $15 \mathrm{~min}$ at room temperature, the cultures were rinsed with PBS, and autofluorescence was quenched with three 5 min incubations in $10 \mathrm{mg} / \mathrm{ml} \mathrm{NaBH}_{4}$ in PBS. After they were rinsed in PBS, the cultures were postextracted in a graded series of ethanols and then incubated for $1 \mathrm{hr}$ in a blocking solution containing 5\% normal goat serum (Life Technologies) in PBS. The cultures were incubated in primary antibody for $15 \mathrm{hr}$ at $4^{\circ} \mathrm{C}$, rinsed three times in PBS, incubated in blocking solution for $1 \mathrm{hr}$, and then incubated in secondary antibody for $1 \mathrm{hr}$ at $37^{\circ} \mathrm{C}$. Finally, the coverslips were rinsed in PBS and mounted on slides in a glycerol/PBS mixture (Citifluor, UKC, Canterbury, UK) containing $1 \mathrm{mg} / \mathrm{ml}$ $p$-phenylenediamine, and the edges were sealed with nail polish. The primary antibodies were a monoclonal anti- $\beta$-tubulin antibody (mouse IgG1 isotype; Sigma), used at 1:200, that recognizes all forms of tubulin, a rabbit polyclonal (WWTYR; provided by Dr. J. C. Bulinski, Columbia University) that recognizes tyrosinated $\alpha$-tubulin, used at 1:500, and $6-11 \mathrm{~B}-1$, a monoclonal antibody that recognizes the acetylated form of $\alpha$-tubulin (mouse IgG2b; Sigma), used at 1:100. The secondary antibodies used were an FITC-conjugated goat anti-mouse $\operatorname{IgG}\left(\mathrm{Fc}_{\chi}\right.$-specific) and a TRITC-conjugated goat anti-rabbit IgG (Jackson ImmunoResearch), both used at 1:150. All antibodies were diluted in PBS. To examine the distribution of microtubules (labeled by the anti- $\beta$-tubulin antibody), tyrosinated $\alpha$-tubulin, and acetylated $\alpha$-tubulin in oligodendrocytes, the cultures were visualized and images were captured using a Zeiss LSM 410 Laser Confocal Microscope (Carl Zeiss Incorporated, Thornwood, NY). Images were obtained using the Zeiss $100 \times$ Plan-Apochromat objective, with the pinhole adjusted to allow the collection of optical sections of $\sim 0.6 \mu \mathrm{m}$ axial resolution. Optical sections were taken through the cell bodies and processes of oligodendrocytes labeled with the anti- $\beta$-tubulin antibody, with particular attention paid to the presence or absence of discrete microtubule organizing centers in these cells. Additional cover- slips were also examined on a Nikon microscope (Nikon Inc., Melville, NY) equipped with both epifluorescence and phase optics.

\section{Electron microscopy}

Cells grown on plastic tissue culture dishes were fixed in $2 \%$ glutaraldehyde in $0.1 \mathrm{M}$ cacodylate buffer for $20 \mathrm{~min}$ at room temperature. The cultures were then post-fixed in $1 \%$ osmium tetroxide, processed through a graded series of ethanols, and embedded in epoxy resin. After polymerization, the plastic dish was broken away from the resin, and blocks were made from the surface containing the embedded cells. Ultrathin sections were cut parallel to the substratum of the cells, stained with uranyl acetate and lead citrate, and examined on a Philips 410 electron microscope.

\section{Microtubule polarity analysis}

To determine the polarity orientation of the microtubules in oligodendrocyte processes, a modification of the standard "hooking" protocol was used (Heidemann and McIntosh, 1980; Heidemann and Euteneuer, 1982). In this procedure, the cells are lysed and incubated in a microtubule assembly buffer, which contains exogenous brain tubulin, and then processed for electron microscopy. During the incubation, exogenous tubulin assembles onto existing cellular microtubules and forms protofilament sheets that extend laterally. When viewed in cross section the sheets appear as hooks, and the handedness of these hooks indicates the polarity orientation of the parent microtubule. A clockwise hook indicates that the plus $(+)$ end of the microtubule is directed toward the observer, and a counterclockwise hook indicates that the minus (-) end is directed toward the observer. In the present study, cultures were rinsed once with $\mathrm{Ca}^{2+}$ - and $\mathrm{Mg}^{2+}$-free EBSS and then treated at $37^{\circ} \mathrm{C}$ with $1.25 \%$ saponin in a microtubule assembly buffer $(0.5 \mathrm{M}$ PIPES, $1 \mathrm{~mm}$ EGTA, $0.1 \mathrm{~mm}$ EDTA, $1 \mathrm{~mm} \mathrm{MgCl}_{2}$, 2.5\% DMSO, 1 mM GTP) containing $1.2 \mathrm{mg} / \mathrm{ml}$ bovine brain microtubule protein. The cultures were exposed to the buffer for $5 \mathrm{~min}$, before fixation by the addition of an equal volume of $4 \%$ glutaraldehyde in $0.1 \mathrm{M}$ cacodylate buffer, followed by processing into epoxy resin as described above. Before they were sectioned, the embedded cells were visualized by staining with $1 \%$ alkaline toluidine blue, and oligodendrocyte processes were identified on phasecontrast microscopy and marked by scoring the resin. Ultrathin sections were taken perpendicular to the long axes of the processes, mounted on formvar-coated single-slot grids, and stained with uranyl acetate and lead citrate; we took care to ensure that the sections and grids were not inverted during handling. Photographs were taken of the processes, and the direction of the hooks was assessed from the vantage point of the distal end of the oligodendrocyte process, looking toward the cell body. For each oligodendrocyte process examined, hooked microtubules were scored as having clockwise hooks, counterclockwise hooks, ambiguous hooks, or no hooks. The ambiguous category includes microtubules with hooks of both direction and those with hooks that were too short to interpret. For each process, the percentage of interpretable hooks that were clockwise or counterclockwise was determined, and mean + SD was calculated.

\section{Effects of nocodazole on oligodendrocyte microtubules}

Nocodazole treatment. To assess the stability of oligodendrocyte microtubules, glial cultures grown on coverslips were exposed to the microtubule depolymerizing drug nocodazole (Aldrich Chemical, Milwaukee, WI) for $15,30,60,120$, and $360 \mathrm{~min}$. The nocodazole was prepared as a $10 \mathrm{mg} / \mathrm{ml}$ stock in DMSO that was diluted to a final concentration of $10 \mu \mathrm{g} / \mathrm{ml}$ in warmed culture medium, before being added to the cells. After exposure to nocodazole, the cells were fixed, permeabilized, and prepared for indirect immunofluorescence as described above. Additional control coverslips that had not been exposed to nocodazole were prepared in the same way. Quantitation of the indirect immunofluorescent labeling of the cells with the mouse monoclonal anti- $\beta$-tubulin antibody was used as a measure of the amount of tubulin in the control cells and the amount remaining in cells exposed to nocodazole. Cells labeled with fluorescent antibodies were examined using the Zeiss LSM 410 Laser Confocal Microscope and the $100 \times$ Plan-Apochromat objective, as described above. For the quantitation of microtubule polymer mass after exposure to nocodazole, 12 oligodendrocytes were randomly selected from one coverslip per treatment group, and black-and-white images were captured with the pinhole fully open; the same brightness and contrast settings were used throughout. The fluorescence intensity of each cell was then quantitated using National Institutes of Health-Image (National Institutes of Health, Bethesda, MD). After the background fluorescence 
intensity was subtracted from each image, a value for tubulin polymer mass was calculated for each cell and expressed in arbitrary fluorescence units (AFUs). In addition, the fluorescence intensity of each oligodendrocyte cell body was measured separately and subtracted from the total for each cell to give a measurement of intensity in the processes. These values were then used in the analysis described below. Because the LSM microscope is equipped with photomultiplier tubes that are linear with regard to their detection of fluorescent intensities, differences in fluorescence intensity accurately reflect differences in microtubule mass. To minimize the variation between cells attributable to experimental techniques, all antibody treatments were performed at the same time, using the same reagents under the same experimental conditions. All the samples were analyzed within $48 \mathrm{hr}$ of antibody labeling, and photobleaching was kept to a minimum. Separate coverslips were also examined on a Nikon microscope equipped with both epifluorescence and phase optics.

Analysis of the kinetics of nocodazole-induced microtubule depolymerization. A modeling approach was used to investigate the kinetics of nocodazole-induced microtubule depolymerization in oligodendrocytes. On the basis of the results of previous investigations in neurons (Baas et al., 1991), it was initially hypothesized that oligodendrocytes have two types of tubulin polymer that differ in their sensitivity to nocodazole. A nonlinear regression analysis was therefore used to model the data with a two-compartment model of the following general form: $y=\left(A e^{-B t}\right)+$ $\left(C e^{-D t}\right)$, where $y=$ total amount of tubulin in AFUs, $t=$ time in nocodazole, and $A>C$ and $B>D$.

In this model the expression $A e^{-B t}$ describes the kinetics of a more rapidly depolymerizing, or labile, subset of microtubules, and the component $C e^{-D t}$ refers to the more slowly depolymerizing, or more stable, microtubules. In addition, on the basis of the appearance of the tubulin fluorescence in oligodendrocytes exposed to nocodazole, the data from the cell bodies and the cell processes were also described by twocompartment models of the same general form as that described above. The nonlinear regression was performed using the NLIN procedure of SAS (SAS Institute, Cary, NC). A log transformation was used to stabilize the variance of the raw data, and residuals were analyzed to ensure that the assumptions of the model were satisfied. The values of $A, B, C$, and $D$ obtained from the regression were used to plot theoretical curves to describe the kinetics of the microtubules in the whole oligodendrocytes, cell bodies, and cell processes. The observed data values were also plotted on the same axes.

For the rapidly depolymerizing and slowly depolymerizing forms of polymer, the values of the parameters $A$ and $C$, respectively, give the amount of each type of microtubule (expressed in AFUs) present at time 0 . These values were used to calculate the relative amounts of each type of microtubule in the different regions of the oligodendrocytes. The values of $B$ and $D$ were used to estimate half times for depolymerization of each subpopulation of microtubules.

\section{RESULTS}

\section{Indirect immunofluorescence}

When the glial cultures were examined by phase microscopy, oligodendrocytes were easily recognized on the basis of their morphology. These cells have a small soma of $\sim 10 \mu \mathrm{m}$ in diameter. A number of large processes emerge from the cell body and branch numerous times, giving rise to progressively smaller processes that finally terminate in a fringe of fine processes around the periphery of the cell. Figure 1 illustrates the distribution of microtubules, labeled with the anti- $\beta$-tubulin antibody, in a typical oligodendrocyte in vitro. In these images from the confocal microscope the microtubules have a filamentous appearance and are distributed throughout the oligodendrocyte cell body and both the large and fine processes. In the periphery of the cell the microtubules appear to be oriented parallel to the long axes of the processes, and in the cell body they have a mesh-like organization throughout the cytoplasm. Optical sections taken through the cell bodies of several oligodendrocytes did not reveal the presence of any discrete microtubule organizing centers (Fig. 1).

Oligodendrocytes labeled with the anti-tyrosinated $\alpha$-tubulin antibody showed an appearance similar to cells labeled with the general $\beta$-tubulin antibody, when examined with both epifluorescence optics and confocal microscopy. Tyrosinated tubulin seemed to be present in the cell bodies and large and small processes of these cells and showed the same filamentous distribution. The distribution of acetylated $\alpha$-tubulin, demonstrated with the 6-11B-1 antibody, was similar; however, unlike the tyrosinated tubulin, acetylated tubulin did not seem to be present at the most distal tips of the very fine oligodendrocyte processes (data not shown).

\section{Electron microscopy}

EM examination of cultured oligodendrocytes confirmed the results of the indirect immunofluorescent labeling. Thus microtubules were found throughout the cell bodies and processes of these cells. In the cell bodies the microtubules were scattered through the cytoplasm and were seen in both transverse and longitudinal section (Fig. $2 A$ ). Centrioles occasionally were found in the oligodendrocyte cell body, located close to the nucleus, and in proximity to the Golgi apparatus (Fig. 2). The centrioles that were identified were sometimes associated with a small number of microtubules radiating from the pericentriolar region (Fig. 2A), whereas others showed no association with microtubules (Fig. $2 B$ ). In the largest oligodendrocyte processes (Fig. 3), which emerged directly from the cell body, microtubules were prominent, with variable spacing between them, and little evidence of tight bundling (Fig. 4A). These processes also contained ribosomes, both single and clustered (Figs. 3, 4A), and mitochondria. Granular structures, $\sim 0.5 \mu \mathrm{m}$ in diameter, were also noted in oligodendrocyte cell bodies and processes (Figs. $2 A, 4 A$ ). These had the appearance of dense accumulations of ribosomes. As the processes divided, microtubules continued into the daughter branches and were consistently present as further process subdivision occurred (Fig. 3). The finest processes at the periphery of the oligodendrocyte were frequently seen to contain one or two microtubules and the fine granular material typical of the oligodendrocyte cytoplasm, bounded by plasma membrane (Figs. 4B,C).

\section{Microtubule polarity analysis}

Table 1 summarizes the results of the analysis of the polarity orientation of microtubules in oligodendrocyte processes, using a modified hooking procedure. These results clearly show that the orientation of microtubules is uniform in small oligodendrocyte processes and nonuniform in larger processes. The percentage of hooked microtubules was found to be high (Table 1, Fig. 5). A total of 26 oligodendrocyte processes were examined, and of these 13 were defined as "large" (4-10 $\mu \mathrm{m}$ in diameter) and 13 were designated as "small" processes $(<1.5 \mu \mathrm{m})$. All of the large processes and three of the small processes were of known orientation. Thus in each of these it was known that the hooks on the microtubules were being viewed from the vantage point of the end of the process, looking toward the cell body. The remaining 10 small processes were sectioned incidentally while the identified processes were examined; thus they were of unknown orientation. For these processes, the direction of the hooks was designated as being the "majority" or "minority" direction. The results in Table 1 show that in the large oligodendrocyte processes, $80.5 \%$ $( \pm 16.4 \%)$ of microtubules are oriented with their plus ends distal to the cell body. The percentage of clockwise hooks in the large processes ranged from 50 to $100 \%$. Four processes within this group had $>90 \%$ clockwise hooks, and if these were not included in the final calculation, the percentage of microtubules with plus 

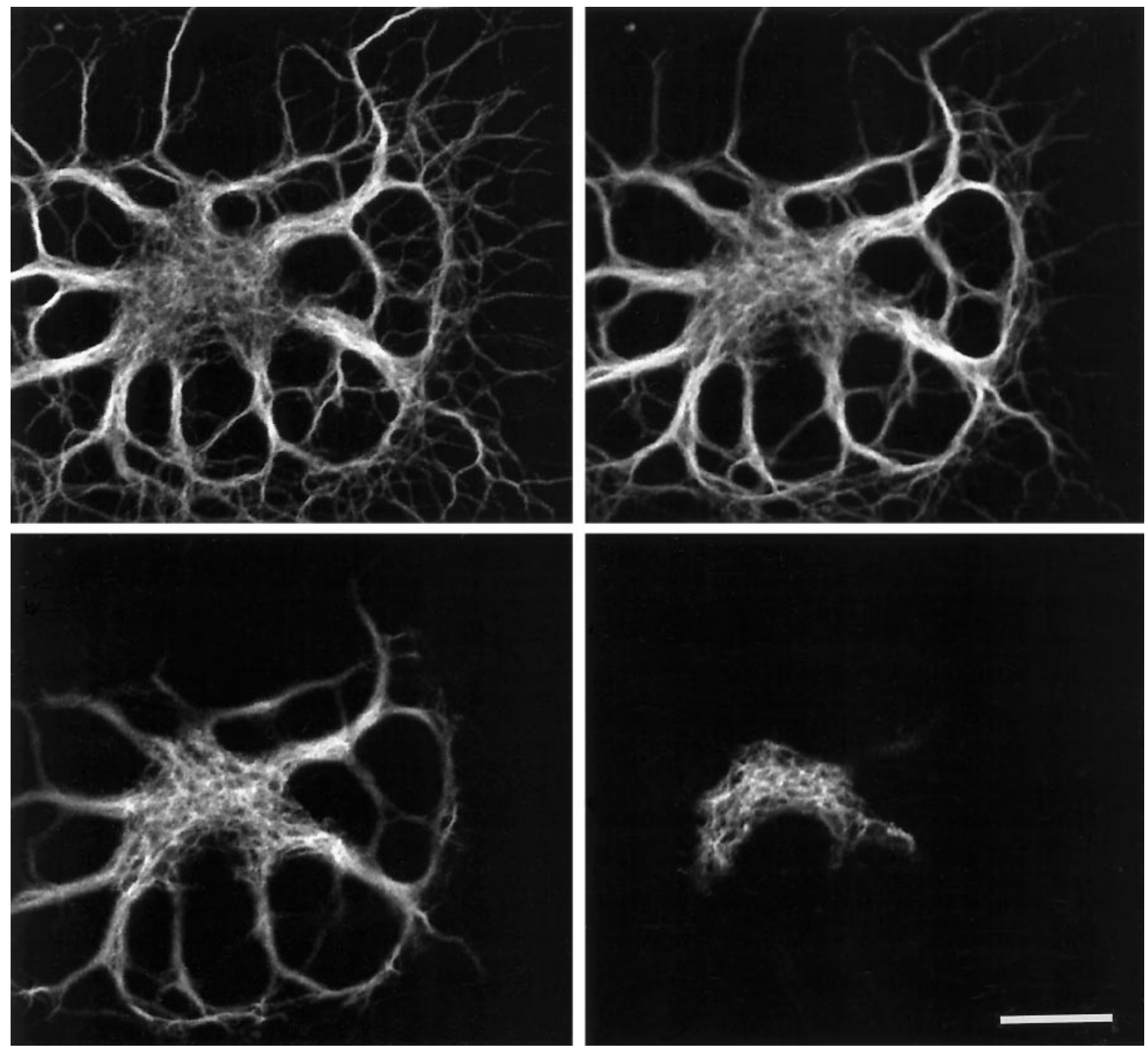

Figure 1. Distribution of microtubules in the cell body and processes of a cultured oligodendrocyte. Optical sections of $\sim 0.6 \mu \mathrm{m}$ axial resolution through an oligodendrocyte labeled with an anti- $\beta$-tubulin primary antibody and an FITC-labeled secondary antibody, and examined by confocal microscopy. Microtubules are present throughout the cell body and processes of this cell and have a filamentous appearance, forming a meshwork in the perinuclear cytoplasm and parallel arrays in the processes. There is no evidence of discrete microtubule organizing structures in this cell. Scale bar, $10 \mu \mathrm{m}$.

ends distal to the cell body fell to $72.4( \pm 12.8 \%)$ in the large oligodendrocyte processes. Figure 5 illustrates the typical appearance of hooked microtubules in small oligodendrocyte processes. In the small processes of known orientation, the microtubules were uniformly oriented, with plus ends distal to the cell body in $95.8 \%( \pm 7.2 \%)$. For the 10 small oligodendrocyte processes of unknown orientation, $97.6 \%( \pm 5.2 \%)$ of the microtubules had hooks in the majority direction, indicating that microtubule polarity was also uniform in these processes. Given that the small processes of known orientation had uniformly plus-end distal microtubules, this was also assumed to be true for the processes of unknown orientation. Thus the percentage of microtubules with plus ends distal to the cell body was calculated to be $97.2 \%$ $( \pm 5.5 \%)$ in the small processes.

\section{Effects of nocodazole on oligodendrocyte microtubules}

Appearance of cells exposed to nocodazole

When viewed by confocal microscopy and epifluorescence, the control oligodendrocytes showed immunofluorescence of the cell body and large and small processes, reflecting the distribution of microtubules in these cells (Fig. 6A). After 15 min of exposure to nocodazole, however, there was an obvious reduction in fluorescence intensity throughout the whole cell, with a marked decrease in the small processes (Fig. $6 B$ ). With further exposure to nocodazole, there was continued loss of fluorescence intensity from the processes, although the cell body showed little change with time (Fig. 6C,D). The loss of intensity from the processes appeared more marked in those of small diameter, and after $6 \mathrm{hr}$ exposure to nocodazole most of the labeled microtubules in the oligodendrocytes appeared to be in the cell body and large processes (Fig. $6 D)$. When the labeled cells were examined with epifluorescence and phase optics, it was found that oligodendrocytes retained their small processes after exposure to nocodazole, confirming that the loss of fluorescence intensity was attributable to loss of microtubules rather than loss of the processes themselves.

\section{Kinetics of nocodazole-induced microtubule depolymerization}

Three separate nonlinear regression analyses were performed to describe the kinetics of the rapidly depolymerizing and slowly 


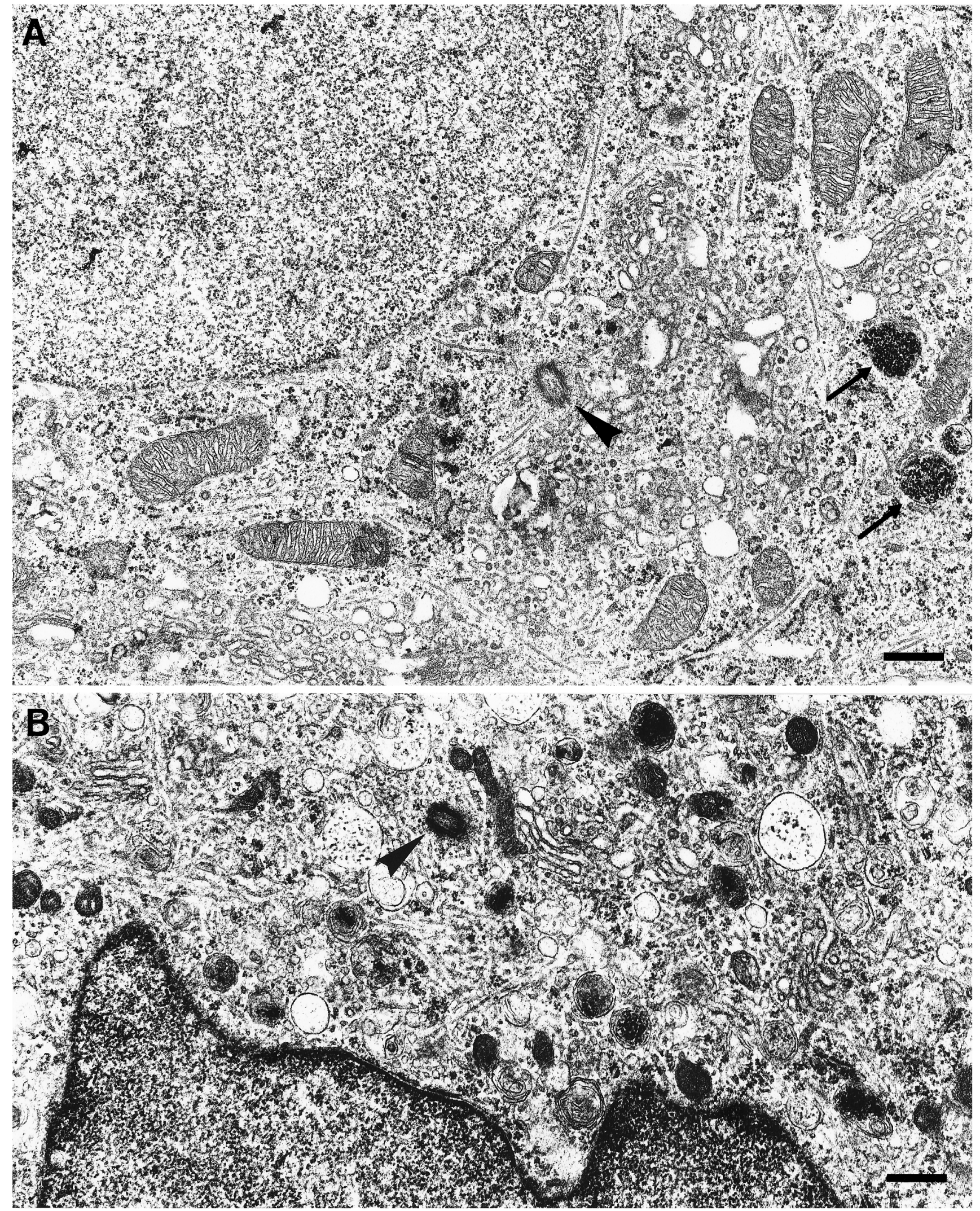

Figure 2. Electron micrographs of the perinuclear region of cultured oligodendrocytes. Both cells contain scattered microtubules, and a centriole can be seen in each (arrowheads). In $A$, a number of microtubules appear to radiate from the pericentriolar region, whereas no microtubules appear to be associated with the centriole in $B$. Granules are present in the cytoplasm of the oligodendrocyte in $A$ (arrows). These appear to consist of accumulations of ribosomes. Scale bars, $0.5 \mu \mathrm{m}$. 


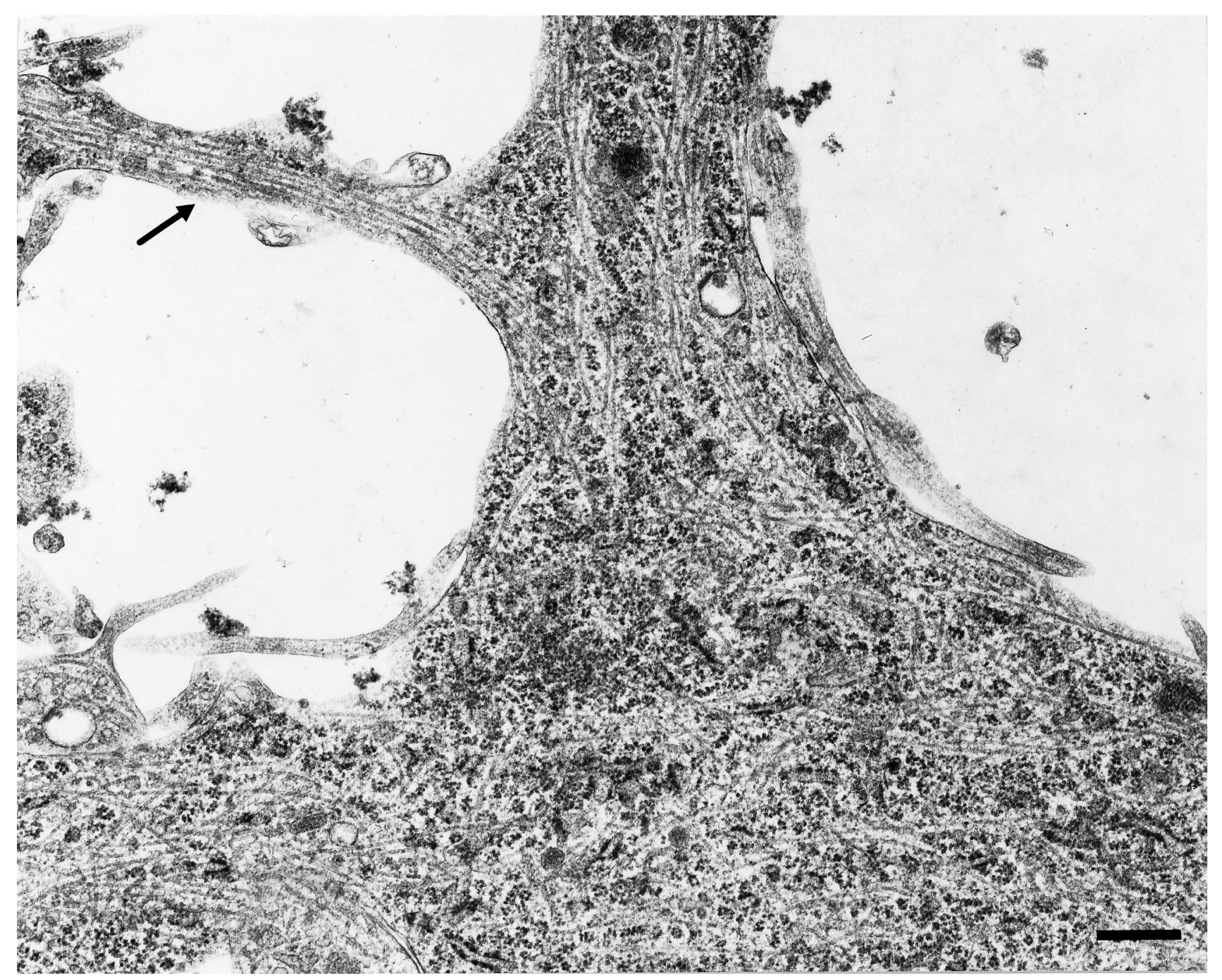

Figure 3. Electron micrograph demonstrating the branching of oligodendrocyte processes and the presence of microtubules in the branches. In the widest process the microtubules are generally parallel to the long axis of the process, although they also appear to curve. Ribosomes are prominent in the wide processes but infrequent in the narrow process (arrow). Scale bar, $0.5 \mu \mathrm{m}$.

depolymerizing microtubules in oligodendrocytes. Initially the data were summarized by a single two-compartment model to describe the whole cell; however, the images of the fluorescently labeled cells suggested that the microtubules in the oligodendrocyte cell bodies and processes depolymerized with different kinetics in the presence of nocodazole. Therefore two additional models were proposed to describe these two regions separately. Figure 7 shows the theoretical curves predicted for each model, together with the experimental data from the whole cell, the oligodendrocyte cell body, and the processes. Table 2 summarizes the model used to describe each region and the values of the parameters $A$, $B, C$, and $D$ obtained from the nonlinear regression analyses. These results show that of the total tubulin in oligodendrocytes, $73 \%$ is present in the processes.

For the whole oligodendrocyte (Fig. 7a), the amount of tubulin, measured in AFUs, shows an initial rapid decline in the presence of nocodazole (described by the $A e^{-B t}$ component of the model), followed by a slower decrease (described by the $C e^{-D t}$ component). From the values of $A$ and $C$ it can be calculated that of the total tubulin in the oligodendrocyte, $66 \%$ depolymerizes rapidly in the presence of nocodazole, and $34 \%$ is more stable in the presence of the drug. The estimated half times for depolymerization of these two components are 4.2 and $628 \mathrm{~min}$, respectively. The kinetics of microtubules in the oligodendrocyte processes (Fig. $7 b$ ) was similar to that of the whole cell, with the presence of a rapidly depolymerizing component and a more stable population of microtubules. The rapidly depolymerizing microtubules accounted for $66 \%$ of the total tubulin polymer in the processes and had an estimated half time for depolymerization of $3.9 \mathrm{~min}$. The more stable tubulin accounted for $34 \%$ and gave an estimated half time of $389 \mathrm{~min}$.

The regression analysis of the data for the oligodendrocyte cell bodies (Fig. 7c) showed that the value of the component $D$ was not significantly different from zero. Therefore the model used to describe this region of the cell was of the form $y=A e^{-B t}+C$. The $A e^{-B t}$ component describes the rapidly depolymerizing microtubules, and $C$ represents a population of microtubules that do not seem to depolymerize in the presence of nocodazole. The rapidly depolymerizing tubulin accounts for $65 \%$ of the total microtubule mass of the cell body, and the highly stable microtubules account 


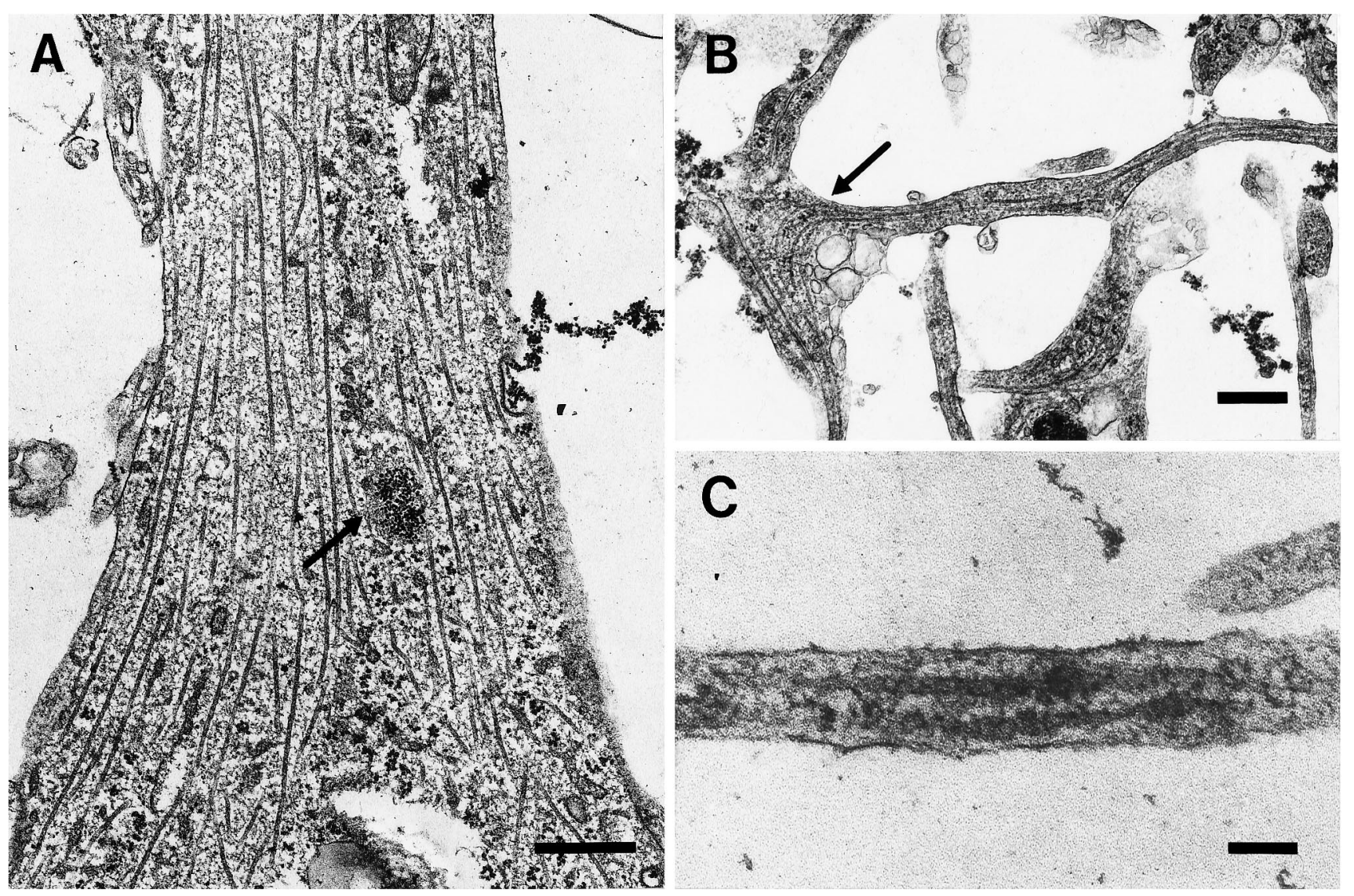

Figure 4. Microtubules are present in oligodendrocyte processes of different sizes. These electron micrographs demonstrate that microtubules are present in both large $(A)$ and small $(B, C)$ oligodendrocyte processes. In $A$, the spacing between the microtubules is irregular. Ribosomes are also present and appear to be clumped together (arrow) as described in Figure $2 A$. In $B$, microtubules appear to curve around the branch point of a small process (arrow). The process in $C$ was found at the periphery of an oligodendrocyte, and although only $\sim 0.15 \mu \mathrm{m}$ in width, it contains two microtubules in this view. Scale bars: $A, B, 0.5 \mu \mathrm{m} ; C, 0.1 \mu \mathrm{m}$.

Table 1. Direction of microtubule hooks in oligodendrocyte processes

\begin{tabular}{lclll} 
Process size & Number & $\% \mathrm{CW}( \pm \mathrm{SD})$ & $\% \mathrm{CCW}( \pm \mathrm{SD})$ & $\%$ Hooked \\
\hline Large & 13 & $80.5( \pm 16.4)$ & $19.5( \pm 16.4)$ & $86.3( \pm 8.4)$ \\
Small & 3 & $95.8( \pm 7.2)$ & $4.2( \pm 7.2)$ & $93.3( \pm 11.5)$ \\
Small & $13^{a}$ & $97.2( \pm 5.5)$ & $2.8( \pm 5.5)$ & $91.0( \pm 9.0)$
\end{tabular}

The values for clockwise $(\mathrm{CW})$ and counterclockwise $(\mathrm{CCW})$ hooks are means of the values from each process, expressed as a percentage of the total number of interpretable hooks. The hooking percentage is expressed as a mean of the percentage of the total number of microtubules that were hooked in each process. The 13 large and 3 small processes were viewed from the vantage point of the end of the process, looking toward the cell body.

${ }^{a}$ The 13 small processes include the 3 processes of known orientation and the 10 processes of unknown orientation. The latter are described separately in Results. The two data sets were combined after assuming that all the small processes contain microtubules with a uniformly plus-end distal orientation.

for $35 \%$. The estimated half time for depolymerization of the more labile tubulin could be calculated to be $5.0 \mathrm{~min}$; however, the theoretical decay of this component to half of its original value does not occur. There is no evidence of a decay of the stable component over the time span of these data, and thus a half time cannot be calculated for these microtubules.

\section{DISCUSSION}

The primary function of the oligodendrocyte is the myelination of axons in the CNS. Knowledge of the spatial organization, polarity orientation, and stability properties of oligodendrocyte microtubules is central to understanding how this cell achieves and maintains its specialized morphology and how it is able to spatially regulate and coordinate the transport of lipids, proteins, and mRNAs essential for myelin synthesis and maintenance. The present studies were performed on oligodendrocytes grown in the absence of neurons, and future experiments should address the influence of axons on the microtubule arrays of these cells. Axons have been shown to regulate the distribution of microtubules in Schwann cells (Kidd et al., 1996). Unlike the myelin-forming cells of the PNS, however, oligodendrocytes in vitro are phenotypically very similar to their counterparts in vivo (Kachar et al., 1986; Knapp et al., 1987; Barry et al., 1996). Because the neuron is a highly morphologically specialized cell of the nervous system in which the microtubule array plays a central role in the determination of cell form and function, this cell 


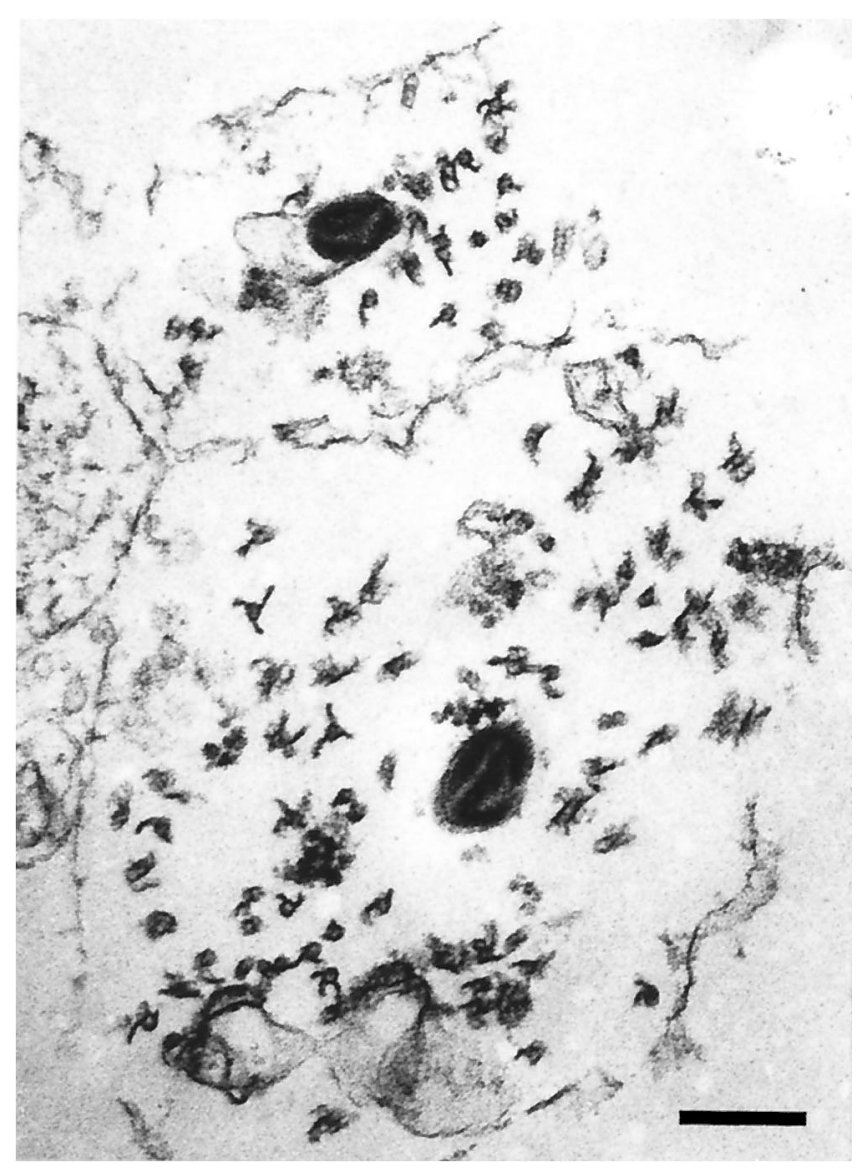

Figure 5. Electron micrograph of "hooked" microtubules in oligodendrocyte processes. The orientation of these two small processes is unknown, but almost all the interpretable hooks are counterclockwise in this view. Scale bar, $0.2 \mu \mathrm{m}$.

type will be used as a model in discussing the properties of oligodendrocyte microtubules.

\section{The organization of oligodendrocyte microtubules}

The presence of centrioles and microtubules in oligodendrocytes in vivo and in vitro has been described by many authors (Mori and Leblond, 1970; Gonatas et al., 1982; Kachar et al., 1986; Kuhlmann-Krieg et al., 1988; Peters et al., 1991), although there are no descriptions of an association between these organelles. In the present EM study, the vast majority of microtubules present in oligodendrocytes had no association with any structures with the appearance of microtubule-organizing centers. Similarly, discrete organizing centers were not identified in those cells in which fluorescently labeled microtubules were examined by confocal microscopy. EM studies suggest that neuronal centrosomes are also associated with very small numbers of microtubules (Lyser, 1968; Baas and Joshi, 1992); however, it has been demonstrated recently that the neuronal centrosome is in fact a highly potent microtubule nucleating structure (Yu et al., 1993), with microtubules rapidly released from the centrosome and then subsequently transported into axons (Ahmad and Baas, 1995) and dendrites (Sharp et al., 1995). It may be hypothesized that a similar mechanism exists in the oligodendrocyte, with microtubules initially nucleated at the centriole, before their release and distribution throughout the oligodendrocyte cell body and processes.

\section{Polarity orientation of oligodendrocyte microtubules}

Microtubules are intrinsically polar structures, with the plus end of the microtubule favored for assembly over the minus end (Bergen and Borisy, 1980). The present studies show that microtubules in large oligodendrocyte processes are organized with a nonuniform polarity orientation. Approximately $80 \%$ have their plus ends distal to the cell body, and $20 \%$ of the microtubules have their plus ends directed toward the cell body. In contrast, there is strong evidence for small oligodendrocyte processes containing microtubules with a uniformly plus-end distal polarity orientation. The findings in large oligodendrocyte processes are similar to those in Schwann cells (Kidd et al., 1994). The Schwann cell is the myelin-forming cell of the peripheral nervous system, and an analysis of polarity orientation of microtubules in the cytoplasmic transport channels of these cells indicated that $75 \%$ had their plus ends directed away from the perinuclear region.

Microtubule polarity orientation in neurons has been studied in some detail, showing conclusively that axonal microtubules have a uniformly plus-end distal orientation (Burton and Paige, 1981; Heidemann et al., 1981; Baas et al., 1988), in contrast to a mixed polarity orientation in the dendrites (Baas et al., 1988). During neuronal maturation, the developing axon maintains the uniform microtubule polarity orientation of its precursor minor process, whereas the remaining processes acquire the morphological features of mature dendrites at the same time as they acquire a population of minus-end distal microtubules (Baas et al., 1989). At all stages of dendritic development the microtubules at the distal end of the process have a uniform plus-end distal polarity orientation (Baas et al., 1988, 1989). Thus, in both axons and dendrites, the plus ends of microtubules extend into the growth cones, and it seems that the presence of microtubules with this orientation is necessary for process outgrowth and elongation (Yamada et al., 1970; Baas et al., 1987, 1989). From the results of the present study, it may be hypothesized that the outgrowth of new oligodendrocyte processes occurs at the plus ends of microtubules. The newly formed small processes contain uniformly plus-end distal microtubules, with microtubule assembly and process elongation occurring concurrently at the process tips. As the processes enlarge they acquire a population of minus-end distal microtubules, perhaps through transport of microtubules from the proximal regions of the cell, with their minus ends leading, as has been suggested in dendrites (Sharp et al., 1995), or through local nucleation and assembly within the oligodendrocyte process.

\section{The stability properties of oligodendrocyte microtubules}

The results of the nonlinear regression analysis suggest that oligodendrocyte microtubules can be resolved into at least three distinct subpopulations that differ in their kinetics of depolymerization in the presence of nocodazole. Because the values for $B$ were very close in the separate models for the cell body and processes, the labile microtubules in each region may be part of the same population, accounting for $\sim 65 \%$ of the total and depolymerizing with a combined estimated half time of $4.2 \mathrm{~min}$. The processes contain a second subpopulation of microtubules that depolymerize slowly, with an estimated half time of $389 \mathrm{~min}$. Within the oligodendrocyte cell body there is a third subpopulation of microtubules that are extremely stable and do not depolymerize in the presence of nocodazole within the time frame of the present study. Therefore, oligodendrocyte microtubule kinetics in the presence of nocodazole may be described by a threecompartment model, although more data are required to test this 

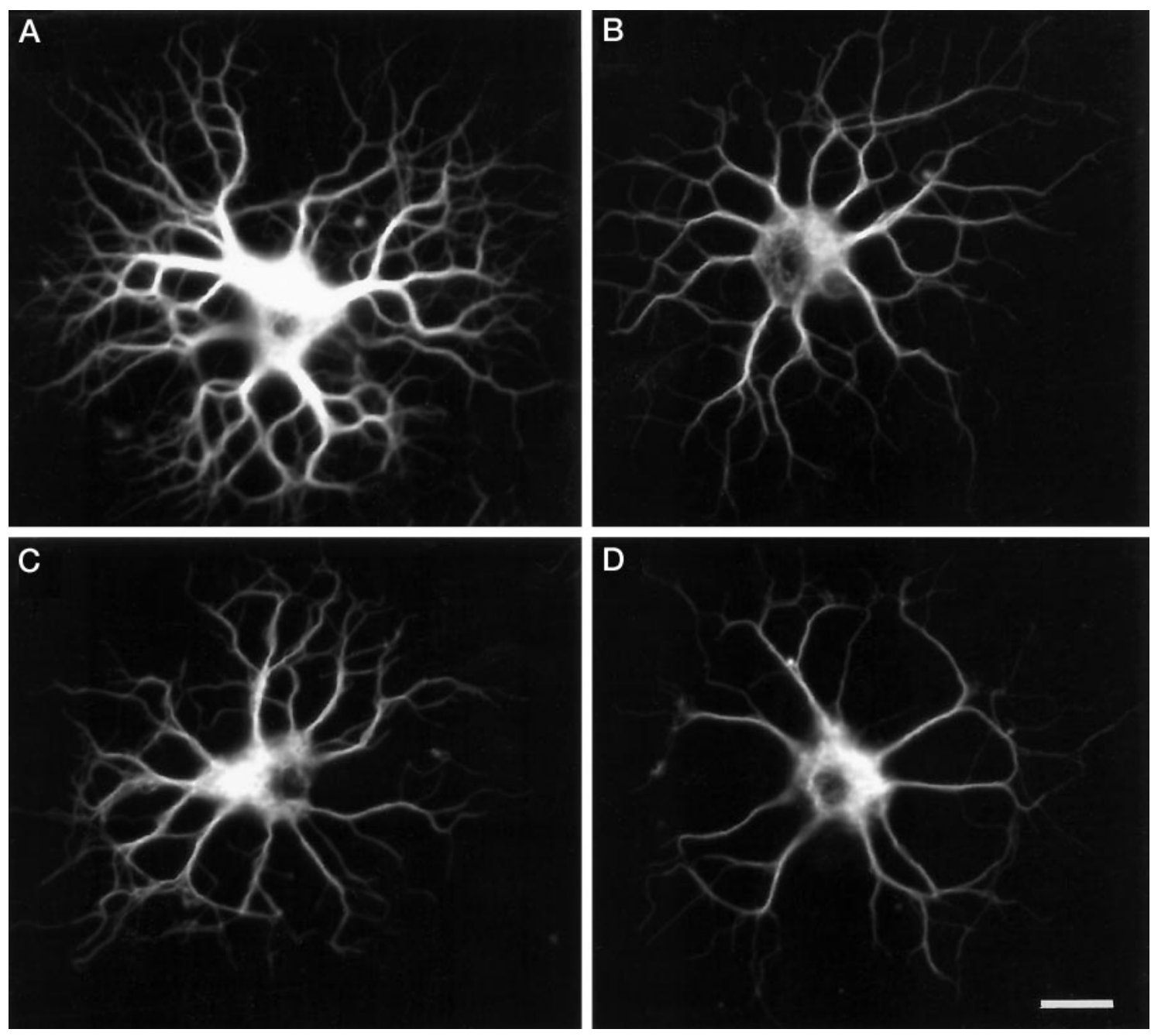

Figure 6. The effect of nocodazole on oligodendrocyte microtubules. Confocal images of a control oligodendrocyte $(A)$ and cells exposed to nocodazole for $15 \mathrm{~min}(B), 1 \mathrm{hr}(C)$, and $6 \mathrm{hr}(D)$. The cells were indirectly immunofluorescently labeled for $\beta$-tubulin, and the same brightness and contrast settings were used to display each image; thus the intensity of fluorescence reflects the amount of tubulin present in each cell. The control cell shows intense labeling of the cell body and processes. After $15 \mathrm{~min}$ exposure to nocodazole, there is a marked overall reduction in fluorescence intensity. Fluorescence intensity decreases further in the processes with continued exposure to nocodazole, although there is little apparent change in the cell body. After $6 \mathrm{hr}$ exposure to nocodazole, most of the tubulin present in the oligodendrocyte appears to be confined to the cell body and larger processes $(D)$. Scale bar, $10 \mu \mathrm{m}$.

hypothesis. In neurons, microtubules can be resolved into two subpopulations: one that is labile and one that is relatively stable in the presence of nocodazole (Baas and Black, 1990; Baas et al., 1991). In these cells, however, the two types of microtubule polymer have been shown to exist as distinct domains on individual microtubules, rather than as separate populations of organelles (Baas and Black, 1990). Immunoelectron microscopic analyses would be required to determine whether this is also the case in oligodendrocytes.

\section{The role of microtubules in the biology of the oligodendrocyte}

The cytoskeletal elements present in oligodendrocytes comprise microtubules and microfilaments (Wilson and Brophy, 1989). Mature oligodendrocytes do not contain intermediate filaments, although oligodendrocyte progenitors have been shown to contain vimentin (Raff et al., 1984). A number of authors have noted a relationship between cytoskeletal elements and myelin constituents (Dyer and Benjamins, 1989; Gillespie et al., 1989; Wilson and Brophy, 1989), and microtubules also seem to play a role in the spatial segregation of myelin protein mRNAs in the oligodendrocyte (Colman et al., 1982; Trapp et al., 1987; Amur-Umarjee et al., 1990).

The distribution of labile and stable microtubules in the oligodendrocyte reflects the functions of the different regions of this cell. In cultured oligodendrocytes, the small processes, which rapidly lose fluorescence intensity in the presence of nocodazole, are likely to be analogous to the processes that in vivo contact and spiral around axons to form the myelin sheath. The presence of a dynamic microtubule array is likely to be central to this early phase of myelin formation. The relatively stable microtubules, also detected in oligodendrocyte processes, may help to maintain the highly branched morphology of the cell, and they serve as a substrate for the transport of organelles and macromolecules. The highly stable microtubules in the cell body of the oligodendrocyte may be similar to a stable population of microtubules described in chick sensory neurons in culture (Letourneau and Wire, 1995). In both cell types this stable perikaryal microtubule array may provide a framework that supports the cell body and mediates the transport of organelles and microtubules. 
A

Whole Cell

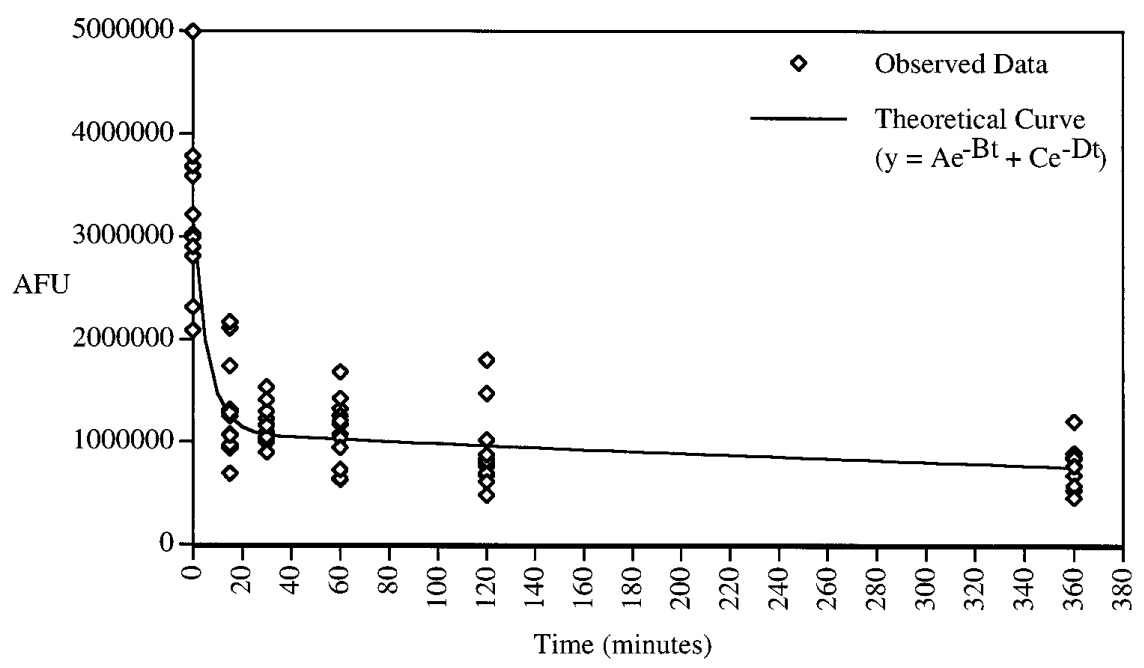

B

Processes

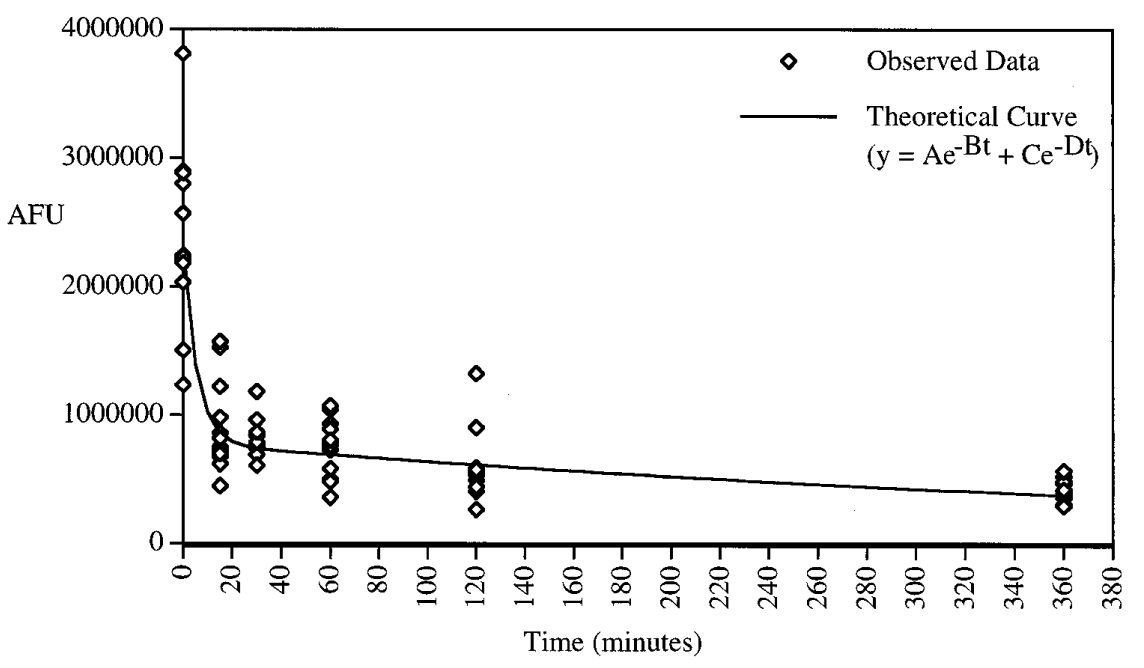

C

Cell Body

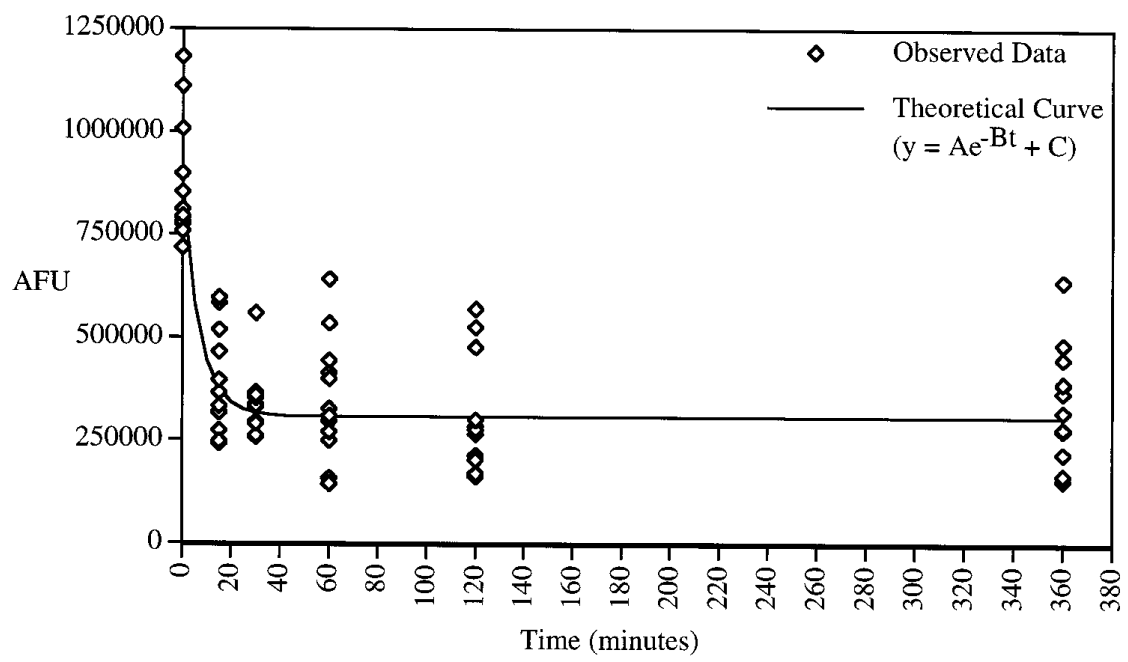

Time (minutes)
Figure 7. Theoretical curves predicted from three separate models describing the kinetics of nocodazole-induced microtubule depolymerization in oligodendrocytes. The nonlinear regression analyses suggest the presence of rapidly depolymerizing and slowly depolymerizing microtubules in the whole oligodendrocyte $(a)$, the processes $(b)$, and the cell body (c). The observed data values are plotted on the same axes as the theoretical curves, with $n=12$ at each time point. The vertical axis represents the total amount of tubulin expressed in arbitrary fluorescence units $(A F U)$. 
Table 2. Values of the parameters $\mathrm{A}, \mathrm{B}, \mathrm{C}$, and $\mathrm{D}$ from the nonlinear regression analysis of nocodazole-induced microtubule depolymerization in the whole oligodendrocyte, the cell body, and the processes

\begin{tabular}{|c|c|c|c|c|c|}
\hline \multirow[b]{2}{*}{ Region } & \multirow[b]{2}{*}{ Model } & \multicolumn{4}{|c|}{ Parameter estimate $( \pm \mathrm{SE})$} \\
\hline & & $A$ & $B$ & $C$ & $D$ \\
\hline Whole cell & $A e^{-B t}+C e^{-D t}$ & $2,085,000( \pm 274,000)$ & $0.1659( \pm 0.0492)$ & $1,085,000( \pm 73,500)$ & $0.0011( \pm 0.0003)$ \\
\hline Processes & $A e^{-B t}+C e^{-D t}$ & $1,510,000( \pm 211,000)$ & $0.1776( \pm 0.0600)$ & $777,000( \pm 55,500)$ & $0.0018( \pm 0.0004)$ \\
\hline Cell body & $A e^{-B t}+C$ (see Results) & $555,000( \pm 88,000)$ & $0.1398( \pm 0.0413)$ & $306,000( \pm 16,500)$ & (see Results) \\
\hline
\end{tabular}

See Results for further details.

It has been proposed that neurons maintain a polarized morphology by organizing their cytoplasmic constituents through interactions between microtubules and microtubule motors (Baas et al., 1988). Such motors may be specifically plus- or minus-enddirected (Walker and Sheetz, 1993), and both types could potentially influence the distribution of organelles and macromolecules in large oligodendrocyte processes, because these contain microtubules of both polarity orientation. The Golgi apparatus of mammalian cells is associated with the minus ends of microtubules (Kreis, 1990). This may explain the exclusion of Golgi elements from axons, because these contain uniformly plus-end distal microtubules (Baas et al., 1988). In contrast, and consistent with the presence of minus-end distal microtubules, Golgi elements are present in the processes of oligodendrocytes in culture (De Vries et al., 1993), suggesting a role for cytoplasmic dynein in their translocation (Kreis, 1990). The Golgi apparatus is involved in the synthesis and processing of a number of myelin constituents (De Vries et al., 1993), including proteolipid protein (Colman et al., 1982) and myelin-associated glycoprotein (Trapp et al., 1989). Thus the presence of Golgi elements in oligodendrocyte processes allows for the synthesis of myelin components in close proximity to the site of assembly of the myelin sheath.

In the present EM studies, ribosomes were detected in large and medium-sized oligodendrocyte processes. This is in contrast to axons in which it is suggested that ribosomes are excluded by the absence of minus-end distal microtubules (Baas et al., 1988). MBP mRNA is known to be present in oligodendrocyte processes (Amur-Umarjee et al., 1990), where it is translocated in the form of granules that associate with microtubules (Ainger et al., 1993). It has been suggested that the sustained directional movement of granules in oligodendrocyte processes is mediated by kinesin (Ainger et al., 1993), a plus-end-directed motor, although there is no evidence to support this hypothesis. The role of minus-enddirected motors should also be considered, and it is tempting to speculate that the motion of the granules may reflect the organization of microtubules in oligodendrocyte processes. In the experiments of Ainger et al. (1993), the granules showed oscillatory movements at branch points in oligodendrocyte processes and were often found preferentially in only one branch. When the granules reached the oligodendrocyte membrane sheets, they showed random circulatory motion or remained immobile (Ainger et al., 1993). If the granules were preferentially transported toward the minus ends of microtubules, then at branch points they might become detached from microtubules and would continue on only if they were able to attach to the plus end of a new microtubule in the daughter branch. If the branch were small and contained only plus-end distal microtubules, the progress of the granule would halt. The absence of minus-end distal microtubules in the fine processes at the periphery of the cell would also lead to immobility, or random motion, of the granules in this region. Although the mechanism of oligodendrocyte granule translocation remains uncertain, it is clear that mRNA transport allows MBP to be synthesized close to the site of assembly of the myelin sheath. This provides a further example of the role of the oligodendrocyte microtubule array in the specialized biology of this cell.

\section{REFERENCES}

Ahmad FJ, Baas PW (1995) Microtubules released from the neuronal centrosome are transported into the axon. J Cell Sci 108:2761-2769.

Ainger K, Avossa D, Morgan F, Hill SJ, Barry C, Barbarese E, Carson JH (1993) Transport and localization of exogenous myelin basic protein mRNA microinjected into oligodendrocytes. J Cell Biol 123:431-441.

Amur-Umarjee SG, Hall L, Campagnoni AT (1990) Spatial distribution of mRNAs for myelin proteins in primary cultures of mouse brain. Dev Neurosci 12:263-272.

Baas PW, Black MM (1990) Individual microtubules in the axon consist of domains that differ in both composition and stability. J Cell Biol 111:495-509.

Baas PW, Joshi HC (1992) $\gamma$-Tubulin distribution in the neuron: implications for the origins of neuritic microtubules. J Cell Biol 119:171-178.

Baas PW, White LA, Heidemann SR (1987) Microtubule polarity reversal accompanies regrowth of amputated neurites. Proc Natl Acad Sci USA 84:5272-5276.

Baas PW, Deitch JS, Black MM, Banker GA (1988) Polarity orientation of microtubules in hippocampal neurons: uniformity in the axon and nonuniformity in the dendrite. Proc Natl Acad Sci USA 85:8335-8339.

Baas PW, Black MM, Banker GA (1989) Changes in microtubule polarity orientation during the development of hippocampal neurons in culture. J Cell Biol 109:3085-3094.

Baas PW, Slaughter T, Brown A, Black MM (1991) Microtubule dynamics in axons and dendrites. J Neurosci Res 30:134-153.

Barry C, Pearson C, Barbarese E (1996) Morphological organization of oligodendrocyte processes during development in culture and in vivo. Dev Neurosci 18:233-242.

Benjamins JA, Nedelkoska L (1994) Maintenance of membrane sheets by cultured oligodendrocytes requires continuous microtubule turnover and Golgi transport. Neurochem Res 19:631-639.

Bergen LG, Borisy GG (1980) Head-to-tail polymerization of microtubules in vitro. J Cell Biol 84:141-150.

Bizzozero OA, Pasquini JM, Soto EF (1982) Differential effect of colchicine upon the entry of proteins into myelin and myelin related membranes. Neurochem Res 7:1415-1425.

Black MM, Baas PW (1989) The basis of polarity in neurons. Trends Neurosci 12:211-214.

Brown MC, Besio Moreno M, Bongarzone ER, Cohen PD, Soto EF, Pasquini JM (1993) Vesicular transport of myelin proteolipid and cerebroside sulfates to the myelin membrane. J Neurosci Res 35:402-408.

Burton PR (1988) Dendrites of mitral cell neurons contain microtubules of opposite polarity. Brain Res 473:107-115.

Burton PR, Paige JL (1981) Polarity of axoplasmic microtubules in the olfactory nerve of the frog. Proc Natl Acad Sci USA 78:3269-3273.

Colman DR, Kreibich G, Frey AB, Sabatini DD (1982) Synthesis and incorporation of myelin polypeptides into CNS myelin. J Cell Biol 95:598-608.

De Vries H, Schrage C, Hoekstra K, Kok JW, Van der Haar ME, Kalicharan D, Liem RSB, Copray JCVM, Hoekstra D (1993) Outstations of the Golgi complex are present in the processes of cultured rat oligodendrocytes. J Neurosci Res 36:336-343.

Dyer CA, Benjamins JA (1989) Organization of oligodendroglial membrane sheets. I. Association of myelin basic protein and $2^{\prime}: 3^{\prime}$-cyclic 
nucleotide 3 '-phosphohydrolase with cytoskeleton. J Neurosci Res 24:201-211.

Gillespie CS, Wilson R, Davidson A, Brophy PJ (1989) Characterization of a cytoskeletal matrix associated with myelin from rat brain. Biochem J 260:689-696.

Gonatas NK, Hirayama M, Stieber A, Silberberg DH (1982) The ultrastructure of isolated rat oligodendroglial cultures. J Neurocytol 11:997-1008.

Heidemann SR, Euteneuer U (1982) Microtubule polarity determination based of conditions for tubulin assembly in vitro. Methods Cell Biol 24:207-216.

Heidemann SR, McIntosh JR (1980) Visualization of the structural polarity of microtubules. Nature 286:517-519.

Heidemann SR, Landers JM, Hamborg MA (1981) Polarity orientation of axonal microtubules. J Cell Biol 91:661-665.

Kachar B, Behar T, Dubois-Dalcq M (1986) Cell shape and motility of oligodendrocytes cultured without neurons. Cell Tissue Res 244:27-38.

Kidd GJ, Andrews SB, Trapp BD (1994) Organization of microtubules in myelinating Schwann cells. J Neurocytol 23:801-810.

Kidd GJ, Andrews SB, Trapp BD (1996) Axons regulate the distribution of Schwann cell microtubules. J Neurosci 16:946-954.

Knapp PE, Bartlett WP, Skoff RP (1987) Cultured oligodendrocytes mimic in vivo phenotypic characteristics: cell shape, expression of myelin-specific antigens, and membrane production. Dev Biol 120:356-365.

Kreis TE (1990) Role of microtubules in the organisation of the Golgi apparatus. Cell Motil Cytoskeleton 15:67-70.

Kuhlmann-Krieg S, Sommer I, Schachner M (1988) Ultrastructural features of cultured oligodendrocytes expressing stage-specific cell-surface markers. Dev Brain Res 39:269-280.

Letourneau PC, Wire JP (1995) Three-dimensional organization of stable microtubules and the Golgi apparatus in the somata of developing chick sensory neurons. J Neurocytol 24:207-223.

Lyser KM (1968) An electron-microscope study of centrioles in differentiating motor neuroblasts. J Embryol Exp Morphol 20:343-354.

Mori S, Leblond CP (1970) Electron microscopic identification of three classes of oligodendrocytes and a preliminary study of their proliferative activity in the corpus callosum of young rats. J Comp Neurol 139:1-30.

Peters A, Palay SL, Webster Hd (1991) The neuroglial cells. In: The fine structure of the nervous system. Neurons and their supporting cells (Peters A, Palay SF, Webster Hd, eds), pp 273-311. Oxford: Oxford UP.

Raff MC, Williams BP, Miller RH (1984) The in vitro differentiation of a bipotential glial progenitor cell. EMBO J 3:1857-1864.

Sharp DJ, Yu W, Baas PW (1995) Transport of dendritic microtubules establishes their nonuniform polarity orientation. J Cell Biol 130:93-103.

Small RK, Riddle P, Noble M (1987) Evidence for migration of oligodendrocyte-type- 2 astrocyte progenitor cells into the developing rat optic nerve. Nature 328:155-157.

Trapp BD (1990) Distribution of myelin protein gene products in actively-myelinating oligodendrocytes. In: Cellular and molecular biology of myelination (Jeserich G, Althaus HH, Waehneldt TV, eds), pp 59-79. Berlin: Springer.

Trapp BD, Moench T, Pulley M, Barbosa E, Tennekoon G, Griffin J (1987) Spatial segregation of mRNA encoding myelin-specific proteins. Proc Natl Acad Sci USA 84:7773-7777.

Trapp BD, Andrews SB, Cootauco C, Quarles R (1989) The myelinassociated glycoprotein is enriched in multivesicular bodies and periaxonal membranes of actively myelinating oligodendrocytes. J Cell Biol 109:2417-2426.

Walker RA, Sheetz MP (1993) Cytoplasmic microtubule-associated motors. Annu Rev Biochem 62:429-451.

Warf BC, Fok-Seang J, Miller RH (1991) Evidence for the ventral origin of oligodendrocyte precursors in the rat spinal cord. J Neurosci 11:2477-2488.

Wilson R, Brophy PJ (1989) Role for the oligodendrocyte cytoskeleton in myelination. J Neurosci Res 229:439-448.

Yamada KM, Spooner BS, Wessells NK (1970) Axon growth: role of microfilaments and microtubules. Proc Natl Acad Sci USA 66:1206-1212.

Yu W, Centonze VE, Ahmad FJ, Baas PW (1993) Microtubule nucleation and release from the neuronal centrosome. J Cell Biol 122:349-359. 